\title{
Campomelic Dysplasia with Sex Reversal Harboring a Novel Frameshift Mutation
}

Ha Na Lee, $\mathrm{MD}^{1}$, Chae Young Kim, $\mathrm{MD}^{2}$, Euiseok Jung, $\mathrm{MD}^{1}$, Beom Hee Lee, MD, $\mathrm{PhD}^{1,3}$, Byong Sop Lee, MD, $\mathrm{PhD}^{1}$, Ellen Ai Rhan Kim, $\mathrm{MD}, \mathrm{PhD}^{1}$, and Ki-Soo Kim, $\mathrm{MD}, \mathrm{PhD}^{1}$

${ }^{1}$ Department of Pediatrics, Asan Medical Center Children's Hospital, Seoul, Korea

${ }^{2}$ Department of Pediatrics, Kyung Hee University Hospital at Gangdong, Seoul, Korea

${ }^{3}$ Medical Genetics Center, Asan Medical Center, University of Ulsan College of Medicine, Seoul, Korea

\section{ABSTRACT}

Campomelic dysplasia (CD) is a rare genetic disease characterized by skeletal dysplasia that also affects several other organ systems. CD is caused by a SOX9 mutation. We here report a case of CD with a 46, XY karyotype and female external genitalia. This child was born with a weight of $3.12 \mathrm{~kg}$ after 37 weeks of gestation. She exhibited a number of characteristic features including a small thoracic cage, bowing of both femurs, clubbed feet, hypoplastic scapula, 11 pairs of ribs, a bell-shaped narrow thorax, micrognathia, macroglossia, a cleft palate, a flattened nasal bridge, and low set ears. She experienced additional distress because of the presence of a tracheal ring and because she had tracheomalacia. $\mathrm{CD}$ was diagnosed through nucleotide sequence analysis. A frameshift mutation, c.235delC (p.Gln79Argfs*31), was identified in the SOX9 gene that has not previously been reported.

Key Words: Campomelic dysplasia; SOX9 gene; Cleft palate

\section{INTRODUCTION}

Campomelic dysplasia (CD) is a rare genetic disease that belongs to a group of lethal skeletal dysplasias. It is inherited as an autosomal dominant disorder. The term campomelia is derived from the Greek word campo (or campto), meaning bent limb ${ }^{1)}$ and is characterized by bowing of the long bones. Campomelia also affects the development of the skeleton, reproductive system, and other organ systems. This disorder is often lifethreatening in newborns because it causes respiratory distress. Another characteristic of this disorder is that most patients manifest male-to-female sex reversal. Further, some patients with the male karyotype (XY) have female or ambiguous genitalia ${ }^{2)}$ caused by a mutation in SOX9, a member of the SOX (SRY-related HMG box) gene family. We here describe such a case involving a frameshift mutation in SOX9 that has not previously been reported.
Received: 24 July 2020

Revised: 31 August 2020

Accepted: 6 September 2020

Correspondence to: Euiseok Jung, MD Department of Pediatrics, Asan Medical Center, University of Ulsan College of Medicine, 88 Olympic-ro 43-gil, Songpa-gu, Seoul 05505, Korea

Tel: +82-2-3010-3372

Fax: +82-2-3010-7302

E-mail: euisjung@amc.seoul.kr
Copyright(c)

By Korean Society of Neonatology.

All right reserved.

This is an Open-Access article distributed under the terms of the Creative Commons Attribution Non-Commercial License (http:// creativecommons.org/licenses/by-nc/4.0), which permits unrestricted non-commercial use, distribution, and reproduction in any medium, provided the original work is properly cited. 


\section{CASE REPORT}

Our CD patient was a female born in 2017 by cesarean section after 37 weeks of gestation to a 29-year-old mother. She was the first child of a healthy, non-consanguineous couple. Her mother was gravida 0 , para 0 . There was no history of skeletal abnormalities on both sides of the family. A prenatal ultrasound demonstrated angulation and bowing of both femurs, contracture of her left knee joint, malalignment of both toes, micrognathia and female external genitalia. A 46, XY karyotype was confirmed by amniocentesis. At birth, her Apgar scores were 2 and 5, res pectively, and endotracheal intubation was performed due to respiratory distress in the delivery room. Her birth measurements were as follows: weight, $3.1 \mathrm{~kg}$ (50th to 90th percentile); length, $45 \mathrm{~cm}$ (10th percentile); and head circumference, $38 \mathrm{~cm}$ ( $>97 \mathrm{th}$ percentile). Her physical features included micrognathia, macro glossia, a cleft palate, a flattened nasal bridge, low set ears, a small thoracic cage, short limbs, anterolateral femoral bowing, clubbed feet, and normal female external genitalia. Laboratory blood tests were normal. A postnatal skeletal radiograph con firmed the bowing of both femurs (Figure 1A) and clubbed feet (Figure 1B), and also revealed a hypoplastic scapula, 11 pairs of ribs, a bell-shaped narrow thorax, and scoliosis (Figure 1C). Echocardiography further revealed a patent foramen ovale without anomalies. Cerebral ultrasonography on the 2nd day post-birth revealed mildly prominent lateral ventricles. Abdomi- nal and genital ultrasonography revealed a vagina and uterus but no ovaries or testicles. The result of brainstem auditory evoked potential was both referred.

We obtained informed consent from the parents to screen for genetic mutations and we isolated peripheral blood genomic DNA for this purpose. Nucleotide sequence analysis revealed a heterozygous c.235delC deletion mutation in exon 1 of the SOX9 gene, which we identified as a previously unreported p.Gln79Argfs*31 frameshift mutation (Figure 2).

Ventilator weaning in this patient failed due to respiratory distress. A tracheal ring and mild tracheomalacia were detected by bronchoscopy. A tracheostomy was performed at 24 days of age. A subsequent video fluoroscopic swallowing study indicated severe dysphagia, which resulted in nasogastric tube feeding. There was one seizure event during the hospitalization period. There were no specific findings from brain magnetic resonance imaging or electroencephalography. Anticonvulsant medications were eventually discontinued since the symptoms had abated. She was discharged 83 days after birth with a home ventilator.

The patient was again hospitalized due to pneumonia at 10 months of age. Palatoplasty and pressure equalization tube in sertion were performed at 12 months of age. A Bayley Scales of Infant and Toddler Development-II evaluation was performed when she was 14 months old. The mental development and psychomotor development indices were both less than 50 . The mental and motor developmental ages according to the raw
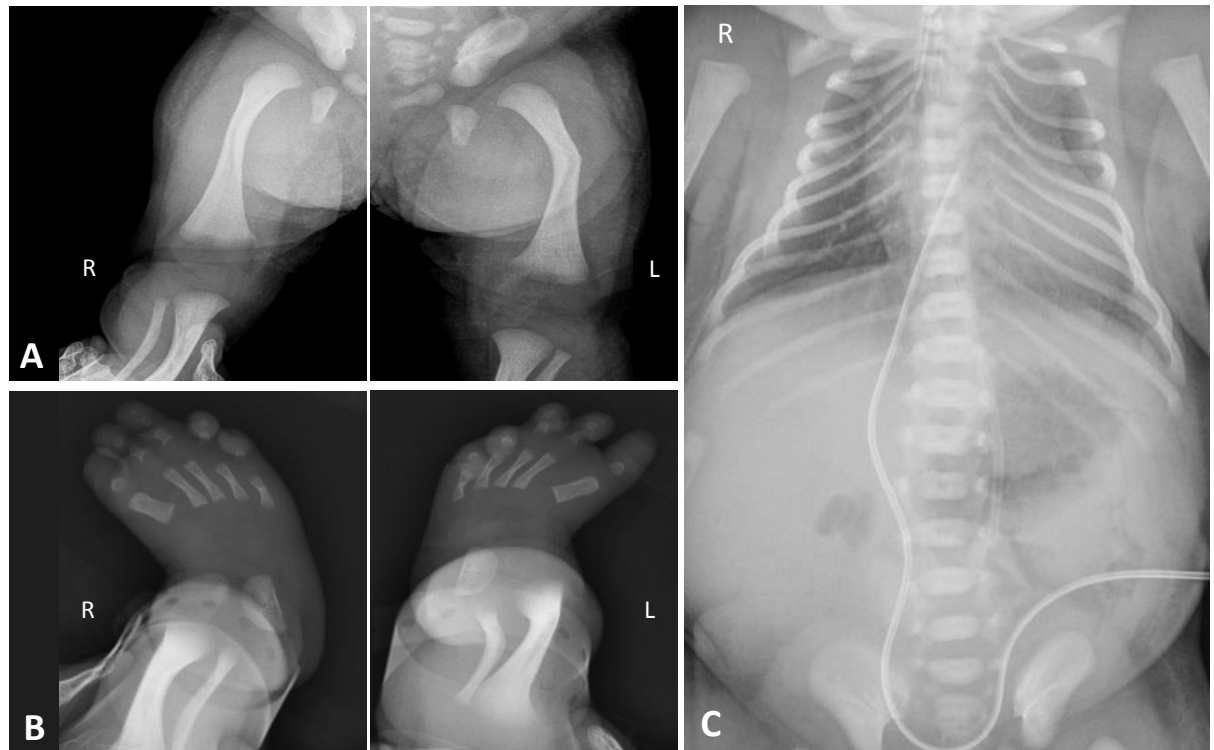

Figure 1. Radiographic examinations of the study patient showing (A) bowing of both femurs, (B) metatarsus adductus in both feet, and (C) 11 pairs of ribs and a bell-shaped thoracic cage. 


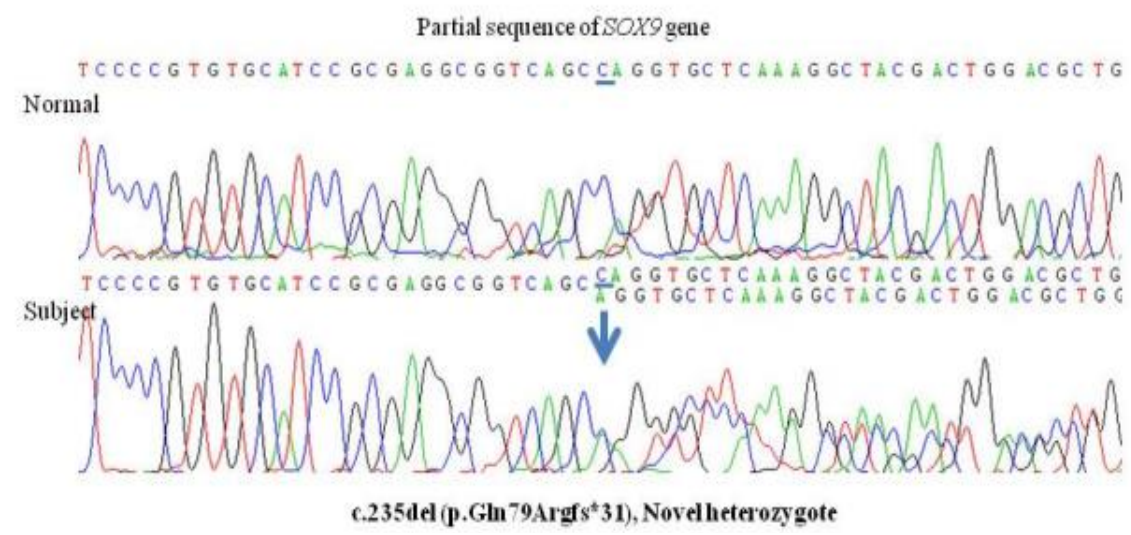

Figure 2. Sequencing analysis of the SOX9 gene in the study patient identified a c. $235 \mathrm{del}(\mathrm{C})$ heterozygous deletion mutation in exon 1 , leading to a premature termination at codon 235 .

scores were 3 and 4 months, respectively, indicating overall de velopmental delay. The number of months according to the scales revealed that she had the cognitive ability of a 3-monthold, the language understanding and expression of an infant less than 1-month-old, the social development of a 2 to 3-monthold, the gross motor skills of an infant less than 1-month-old, and the fine motor skills of a baby of 3 to 4 months of age. At 2 years, her weight, height, and head circumference were $9.4 \mathrm{~kg}$ (<3rd percentile), $72.2 \mathrm{~cm}$ (<3rd percentile), and $47.5 \mathrm{~cm}$ (50th percentile), respectively. She remained completely dependent on others due to her developmental delays. She received a left cochlear implant when she was 2 years old. Although our patient was in a critical condition as a newborn due to respiratory distress, she was eventually maintained in a stable condition through the use of a home ventilator. She is 3 years of age at the time of writing and is undergoing rehabilitation treatment for her developmental delays and we conduct regular follow-ups in an outpatient setting.

\section{DISCUSSION}

$\mathrm{CD}$ is a rare genetic disease but should be considered if there are certain characteristic manifestations in neonates such as macrocephaly with a flattened face and nasal bridge, low-set ears (often with associated deafness), hypertelorism, a long philtrum, micrognathia, and skeletal dysplasia. The skeletal features of CD include bowing of both tibia, angulated femurs, hypo plastic scapula, 11 pairs of ribs, a bell-shaped narrow thorax, and characteristic pretibial skin dimples ${ }^{2}$. This disorder can often be life-threatening due to the onset of respiratory distress during the neonatal period. If CD is clinically suspected, the $S O X 9$ gene should be sequenced to identify possible mutations.

SOX9 is a member of the family of SRY-related high-mobilitygroup box (SOX) transcription factors ${ }^{3)}$. The SOX9 gene is located on the long arm of human chromosome 17. The SOX9 protein HMG box domain shares $71 \%$ similarity with the SRY HMG box and has a proline and glutamine rich region in its activation domain $^{4}$. SOX9 mutations are associated with skeletal dysplasia and sex-reversal phenotypes. However, their precise mechanistic relationship with sex-reversal phenotypes has not been established $^{5)}$. SOX9 regulates chondrogenesis and the expression of cartilage matrix genes in the early stages of development ${ }^{6)}$. It binds to the chondrocyte-specific enhancer of the COL2A1 gene, which encodes type II collagen, the main cartilage matrix protein, and thereby activates it in these cells. SOX9 is also a transcription factor that regulates the differentiation of cartilage cells. Low levels of SOX9 lead to a decrease in COL2A1 expression and thereby cause skeletal abnormalities ${ }^{7,8)}$.

In addition to chondrogenesis, the SOX9 gene plays a role in sex determination and gonadogenesis in the early stages of development. SRY may directly or indirectly control the timing and cell-type specificity of SOX9 expression ${ }^{9}$. X9 regulates the differentiation of Sertoli cells and some SOX9 mutations may cause male-to-female sex reversal ${ }^{2}$. Chondrogenesis is possible only when SOX9 binds cooperatively as a dimer. SOX9 mutations do not always cause sex reversal because the mutant proteins can operate as monomers and bind to the regulatory regions of the sex-determining gene SF1.

Four classes of heterozygous SOX9 mutations were identified 
previously by Bernard et al. ${ }^{10)}$ : (1) amino acid substitutions in the HMG domain; (2) truncations or frameshifts that alter the C terminus; (3) mutations at splice junctions; and (4) chromosomal translocations. In our current case, the frameshift we identified caused a deletion of codon 235 in exon 1 of SOX9 as a heterozygous, c.235delC, variation.

To date, two cases of CD have been genetically confirmed in Korea $^{11,12)}$; however, the p.Gln79Argfs*31 frameshift deletion mutation in our current study has never been reported. This premature termination of the SOX9 protein results in a loss of function, leading to skeletal dysplasia and sexual reversal. As in this case, two previous studies from Korea have reported severe clinical courses: in one case, the patient died of respiratory failure after 4 months, and, at the time of writing, the other patient was 40 months old ${ }^{11,12)}$.

Unlike in Korea, foreign cases are often found who have sur vived for a long time or have been diagnosed with old age. According to Meyer et al. ${ }^{13)}$, there is no correlation between the type and position of mutations within the SOX9 gene among phenotypes. However, in other cases where the CD patients survived, most of the patients exhibited milder symptoms, and it should be noted that the difference determines the severity of symptoms. However, correlations of some degree are observed in those with: (1) chromosomal rearrangement and (2) mosaicism of the SOX9 mutation ${ }^{14,15)}$. De novo translocations or inversions with breakpoints upstream of $S O X 9$ are more likely to lead to the removal of one or more cis-regulatory elements ${ }^{15)}$. According to Mansour et al. ${ }^{14)}$, the father of the patient also has the same SOX9 mutation, but his mutation was clinically silent. These findings were associated with better survival or diagnosis at an older age.

In conclusion, we here report a novel frameshift mutation in the SOX9 gene of a female with a 46, XY karyotype who was born with $\mathrm{CD}$ and male-to-female sex reversal. CD is a very rare and often fatal genetic disorder; however, the early diagnosis and management of related complications in affected children can prevent the deterioration of their clinical condition and improve their quality of life.

\section{ARTICLE INFORMATION}

\section{Ethical statement}

The Institutional Review Board (IRB) approval for the study was received in June 2020. Retrospective data collection was approved and informed consent was waived by the IRB of the Asan Medical Center (IRB No. 2020-1099).

\section{Conflicts of interest}

No potential conflict of interest relevant to this article was reported.

\section{Author contributions}

Conception or design: E.J.

Acquisition, analysis, or interpretation of data: H.N.L.

Drafting the work or revising: H.N.L., C.Y.K., E.J., B.H.L., B.S.L., E.A.R.K., K.S.K.

Final approval of the manuscript: E.J.

\section{ORCID}

Ha Na Lee https://orcid.org/0000-0002-0217-1773

Euiseok Jung https://orcid.org/0000-0003-0693-5627

\section{Acknowledgments}

None

\section{REFERENCES}

1. Unger S, Scherer G, Superti-Furga A. Campomelic dysplasia. In: Adam MP, Ardinger HH, Pagon RA, Wallace SE, Bean LJH, Stephens K, et al., editors. GeneReviews. Seattle: University of Washington, 1993. Available from: https://www.ncbi.nlm.nih. gov/books/NBK1760/.

2. Mansour S, Hall CM, Pembrey ME, Young ID. A clinical and genetic study of campomelic dysplasia. J Med Genet 1995; 32:415-20.

3. Symon A, Harley V. SOX9: a genomic view of tissue specific expression and action. Int J Biochem Cell Biol 2017;87:18-22.

4. Foster JW, Dominguez-Steglich MA, Guioli S, Kwok C, Weller PA, Stevanovic M, et al. Campomelic dysplasia and autosomal sex reversal caused by mutations in an SRY-related gene. Nature 1994;372:525-30.

5. Kwok C, Weller PA, Guioli S, Foster JW, Mansour S, Zuffardi O, et al. Mutations in SOX9, the gene responsible for Campomelic dysplasia and autosomal sex reversal. Am J Hum Genet 1995; 57:1028-36.

6. Hattori T, Muller C, Gebhard S, Bauer E, Pausch F, Schlund $\mathrm{B}$, et al. SOX9 is a major negative regulator of cartilage vascularization, bone marrow formation and endochondral ossification. Development 2010;137:901-11.

7. Lefebvre V, Huang W, Harley VR, Goodfellow PN, de Crom 
brugghe B. SOX9 is a potent activator of the chondrocytespecific enhancer of the pro alphal(II) collagen gene. Mol Cell Biol 1997;17:2336-46.

8. Bell DM, Leung KK, Wheatley SC, Ng LJ, Zhou S, Ling KW, et al. SOX9 directly regulates the type-II collagen gene. Nat Genet 1997;16:174-8.

9. Kent J, Wheatley SC, Andrews JE, Sinclair AH, Koopman P. A male-specific role for SOX9 in vertebrate sex determination. Development 1996;122:2813-22.

10. Bernard P, Tang P, Liu S, Dewing P, Harley VR, Vilain E. Dimerization of SOX9 is required for chondrogenesis, but not for sex determination. Hum Mol Genet 2003;12:1755-65.

11. Kim HY, Yoon CH, Kim GH, Yoo HW, Lee BS, Kim KS, et al. A case of campomelic dysplasia without sex reversal. J Korean Med Sci 2011;26:143-5.
12. Ko JM, Hah JH, Kim SW, Cho TJ, Kim GH, Yoo HW. A Korean girl with campomelic dysplasia caused by a novel nonsense mutation within the SOX9 gene. J Genet Med 2012;9:89-92.

13. Meyer J, Sudbeck P, Held M, Wagner T, Schmitz ML, Bricarelli FD, et al. Mutational analysis of the SOX9 gene in campomelic dysplasia and autosomal sex reversal: lack of genotype/phenotype correlations. Hum Mol Genet 1997;6:91-8.

14. Mansour S, Offiah AC, McDowall S, Sim P, Tolmie J, Hall C. The phenotype of survivors of campomelic dysplasia. J Med Genet 2002;39:597-602.

15. Pfeifer D, Kist R, Dewar K, Devon K, Lander ES, Birren B, et al. Campomelic dysplasia translocation breakpoints are scattered over $1 \mathrm{Mb}$ proximal to SOX9: evidence for an extended control region. Am J Hum Genet 1999;65:111-24. 